\title{
Leading with Integrity - Being Present and Visible
}

Lori Lamont, RN, BN, MPA

President, Academy of Canadian Executive Nurses

Interim President and CEO, Winnipeg Regional Health Authority

An important role for the Academy of Canadian Executive Nurses (ACEN) is the support and the development of new and emerging nurse leaders in our health system. Nurses have many opportunities to lead in their clinical roles, and we see tremendous examples of this formal and informal leadership every day. However, the move to formal leadership positions is one that can be challenging for nurses and, one that ACEN is invested in supporting. As an organization, we have broadened our membership to include these new and emerging leaders, and we are exploring how we can facilitate the use of the LEADS Framework in nursing leadership development. Many of us are familiar with LEADS in our work environment but how do we, as nurse leaders, best support the next generation of leaders?

The majority of contemporary leadership frameworks - including LEADS - are based on the concept of the use of self as a leader. It is often the core or a foundational competency. Yet, why is it as leaders, it is also the one we under-value in our daily work? Recently in a presentation from a professional sports coach, we were challenged as leaders to engage our employees so that they could see themselves as part of the team and for them to see us as leaders in a very visible way.

In today's large and complex healthcare organizations, it is often difficult to be present and visible. As we move up the leadership ladder, more time is spent in the corporate setting and it can be challenging to find the time to be present and visible with staff in their own work settings. Being the photo on the newsletter or the name on the top of the memo is not enough to truly engage staff. Staff must see themselves as part of the team and must see us actively engaged in leading that team. 
In our busy schedules, where we are often double and triple booked, it is tempting to decide that those short opening or closing remarks at a staff event can be delegated to someone else. This is the wrong decision. If we want staff to commit to important changes in clinical practice or quality improvement in our system, they need to believe that as leaders we value these initiatives enough to make our leadership visible. The message that you have made this event a priority in your day does not go unnoticed.

Besides these formal opportunities, it is important for leaders to remember they are always "on-stage." Growing up in a small prairie town, my siblings and I learned early on that people were always watching and our mother would hear about any misbehaviour. I am often reminded of this in my day-to-day work, not that I am misbehaving but that people are watching. They expect to see the leadership and respectful behaviour that is consistent with the mission and values of the organization. If we want the members of our team to commit to these, they need to believe that you are committed. The old addage, seeing is believing was never more true.

In closing, I would encourage all nurse leaders to ensure that they build opportunities to engage directly with staff. The formal opportunities are important but so are those that occur as we are walking in the halls or in the elevators. Exchange pleasantries, smile and if possible lend a hand with the work staff are doing. These small gestures will not only add positive value to your day, they will reinforce for staff that as their leader, you are interested in them and the work they do.

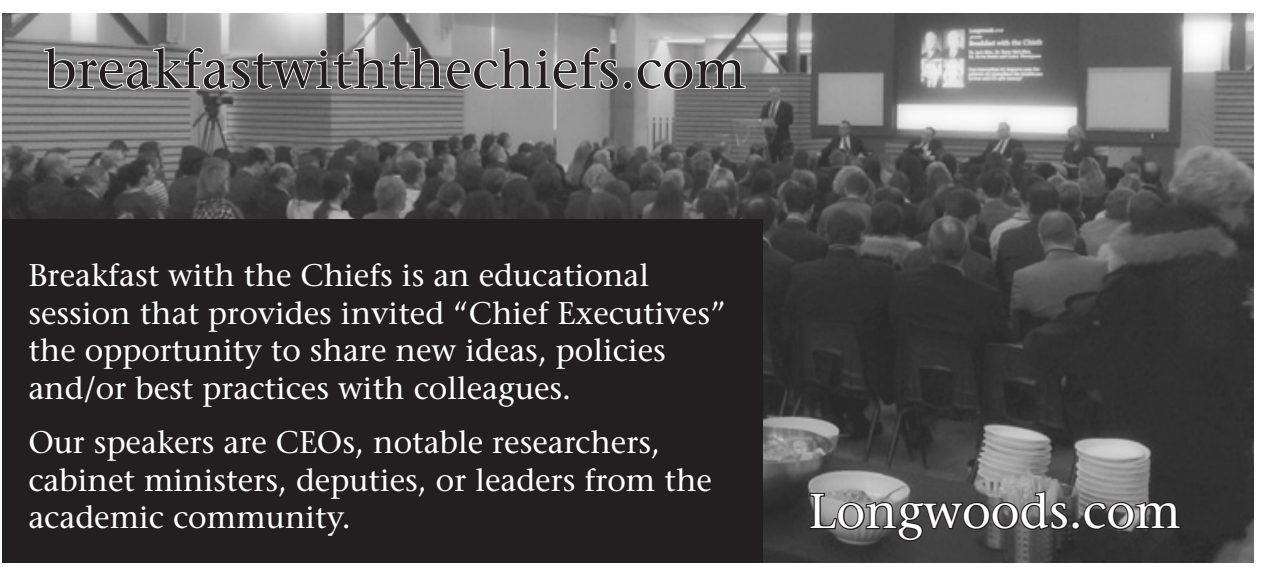

